\title{
Studies on Larval Dispersal in Two Species of Blow Flies (Diptera: Calliphoridae)
}

\author{
Devinder Singh* and Madhu Bala \\ Department of Zoology, Punjabi University, Patiala 147002, Punjab, India
}

\begin{abstract}
The blow fly larvae leave the food source after reaching maturity, and begin to disperse in order to find suitable places for pupariation, a process commonly called postfeeding larval dispersal. Some important aspects of this process were studied by allowing the postfeeding larvae of Chrysomya megacephala (Fabricius) and Chrysomya rufifacies (Macquart) to disperse from the center of a circular arena. The arena was divided into 4 circles starting from the center in order to determine the location of each pupa. The relationship between distance from the center and the weight of each pupa was evaluated statistically. It was observed that the lighter larvae tend to move longer distances. The greatest concentration of pupae was found in distances lesser than $100 \mathrm{~cm}$ in both the species though it was more evident in case of $C$. rufifacies. The study of this dispersal process can be important while estimating the minimum postmortem interval (PMI) of human cadavers during forensic investigations.
\end{abstract}

Keywords: Calliphoridae; Larvae; Dispersal; Pupa; Forensic entomology

\section{Introduction}

Larval dispersal is an important process during the life cycle of blow flies when the larvae leave their food substrate and search for a suitable place to pupariate $[1,2]$. The postfeeding larval stage is normally an irreversible condition when the fully grown third instar larvae stop feeding and give no response towards food. There are several case reports about the use of postfeeding larvae as forensic evidence $[3,4,5,6]$. The larvae may be at risk of predation, parasitization and desiccation during this stage [7]. Godoy et al. [2] and Boldrini et al. [8] investigated experimentally and theoretically the dispersal of postfeeding larvae of $C$. megacephala, $C$. putoria and Cochliomyia macellaria in an earlier study and found that most larvae pupariated close to the food source.

The substrates in which immature stages of blow flies develop are discrete and ephemeral $[9,10]$ and are normally saturated with insects of one or more species. There is often an intense competition for resources [11] which influences the larval behavior. The larvae attempt to feed as much as possible before the complete exhaustion of resources $[1,12,13]$ and start searching for a pupariation site or for another source of food, if they are not mature enough for pupariation. Experimental studies on blow fly larval dispersal have already been done $[14,15]$ and models have been developed on dispersal restricted to one direction based on diffusion equations [16], on statistical analysis of spatial distribution [2] and on non-local interactions [8]. Greenberg [14] compared the dispersal behavior of postfeeding larvae for five species of Calliphoridae and one muscid in 8.1-m-long channels. The results suggested that larvae of Calliphorinae moved farther from the food source, pupariated underground, and produced a thinner puparium as compared to the larvae of Chrysomyinae. The distance to which postfeeding larvae of particular species travel from a corpse is important information for an investigator at the site of corpse who needs to determine if postfeeding larvae are present and where to look for them. In addition, if one wave of blow fly infestation has occurred and the postfeeding larvae have dispersed and are overlooked, the postmortem interval will be incorrectly determined [14]. Similarly, the possibility that postfeeding larvae in the area of the corpse can be from a different carrion source, such as another corpse or an animal carcass, need to be evaluated and the larvae excluded if they are not relevant to the analysis of the corpse being studied.

\section{Materials and Methods}

Colonies of $C$. megacephala and $C$. rufifacies were maintained at room temperature of $27 \pm 2^{\circ} \mathrm{C}$, relative humidity of $70-80 \%$ and photoperiods of $12 \mathrm{~h}$ light and $12 \mathrm{~h}$ dark. When the larvae of a particular egg batch were fully developed, the jar containing 150 to 200 such larvae along with meat was inverted at the center of a circular arena of $4 \mathrm{~m}$ radius established under natural conditions i.e. in the Botanic Garden of Punjabi University, Patiala. Distances between 0 to $100 \mathrm{~cm}, 101$ to $200 \mathrm{~cm}, 201$ to $300 \mathrm{~cm}$ and 301 to 400 $\mathrm{cm}$ from the center of the arena correspond to circles I, II, III and IV respectively. Majority of the pupae were located from the surface of soil while few were collected from a depth less than $1 \mathrm{~cm}$. The distance of each pupariation site from the centre was measured in centimeters with rulers and measuring tapes. The pupae were kept individually in plastic flasks and weighed on an electric balance. They were grouped into three categories according to weight i.e. large pupae weighed more than $37 \mathrm{mg}$ for $C$. megacephala and more than $38 \mathrm{mg}$ for $C$. rufifacies, medium pupae weighed between 33 to $37 \mathrm{mg}$ for $C$. megacephala and between 34 to $38 \mathrm{mg}$ for $C$. rufifacies and small pupae weighed less than $33 \mathrm{mg}$ for $C$. megacephala and less than $34 \mathrm{mg}$ for $C$. rufifacies. The experiment was repeated five times and the averages taken.

\section{Results and Discussion}

Averages, along with and standard deviation for the distances travelled by the larvae from the centre of the circular arena and weight of the pupae in four circles of the arena are presented on Table 1. Considering the distribution for the species in the arena, $35.2 \%$ pupae of Chrysomya megacephala and $63.1 \%$ pupae of Chrysomya

*Corresponding author: Devinder Singh, Department of Zoology, Punjabi University, Patiala 147002, Punjab, India; E-mail: devinder.ss.61@gmail.com

Received September 04, 2010; Accepted October 19, 2010; Published October 22, 2010

Citation: Singh D, Bala M (2010) Studies on Larval Dispersal in Two Species of Blow Flies (Diptera: Calliphoridae). J Forensic Res 1:102. doi:10.4172/21577145.1000102

Copyright: (c) 2010 Singh D, et al. This is an open-access article distributed under the terms of the Creative Commons Attribution License, which permits unrestricted use, distribution, and reproduction in any medium, provided the original author and source are credited. 
Citation: Singh D, Bala M (2010) Studies on Larval Dispersal in Two Species of Blow Flies (Diptera: Calliphoridae). J Forensic Res 1:102. doi:10.4172/2157-7145.1000102

Page 2 of 3

\begin{tabular}{|c|c|c|c|c|c|c|}
\hline \multirow[b]{2}{*}{$\begin{array}{c}\text { Circles } \\
\left(\text { Area }=\pi r^{2}\right)\end{array}$} & \multicolumn{3}{|c|}{ C. megacephala } & \multicolumn{3}{|c|}{ C. rufifacies } \\
\hline & $\begin{array}{l}\text { Average dispersal } \\
\text { distance }(\mathrm{cm}) \text { from the } \\
\text { center of circle } \\
\pm S D\end{array}$ & $\begin{array}{c}\text { Percentage } \\
\text { of pupae in each } \\
\text { circle }\end{array}$ & $\begin{array}{c}\text { Average weight (mg) } \\
\text { of pupae } \\
\text { in each circle } \\
\pm \mathrm{SD}\end{array}$ & $\begin{array}{l}\text { Average dispersal } \\
\text { distance }(\mathrm{cm}) \text { from the } \\
\text { center of circle } \\
\pm S D\end{array}$ & $\begin{array}{l}\text { Percentage of pupae in } \\
\text { each circle }\end{array}$ & $\begin{array}{c}\text { Average weight }(\mathrm{mg}) \\
\text { of pupae } \\
\text { in each circle } \\
\pm \mathrm{SD}\end{array}$ \\
\hline $\begin{array}{c}1 \\
\left(\text { Area }=3.14 \mathrm{~m}^{2}\right)\end{array}$ & $45.6 \pm 24.5$ & 35.2 & $38.9 \pm 4.66$ & $42.8 \pm 15.8$ & 63.1 & $43.4 \pm 5.29$ \\
\hline $\begin{array}{c}\| \\
\left(\text { Area }=9.42 \mathrm{~m}^{2}\right)\end{array}$ & $132.6 \pm 18.7$ & 32.3 & $36.5 \pm 3.98$ & $128.6 \pm 12.6$ & 21.2 & $37.7 \pm 4.98$ \\
\hline $\begin{array}{c}\text { III } \\
\left(\text { Area }=15.7 \mathrm{~m}^{2}\right)\end{array}$ & $225.4 \pm 10.5$ & 24.1 & $34.6 \pm 3.99$ & $214 \pm 6.5$ & 10.4 & $32.8 \pm 4.29$ \\
\hline $\begin{array}{c}I V \\
\left(\text { Area }=21.9 \mathrm{~m}^{2}\right)\end{array}$ & $315 \pm 5.8$ & 8.4 & $31.5 \pm 2.16$ & $306 \pm 1.5$ & 5.3 & $29.9 \pm 2.99$ \\
\hline
\end{tabular}

Table 1: Distance travelled by larvae and weight of pupae (average with standard deviation) of Chrysomya megacephala and Chrysomya rufifacies in four circles of the arena.

rufifacies preferred the circle I while $32.3 \%$ pupae of Chrysomya megacephala and $21.2 \%$ pupae of Chrysomya rufifacies went to circle II. In circle III, $24.1 \%$ pupae of Chrysomya megacephala and $10.4 \%$ pupae of Chrysomya rufifacies were present while only $8.4 \%$ pupae of Chrysomya megacephala and 5.3\% pupae of Chrysomya rufifacies went to circle IV.

The distribution and frequency of pupae in relation to their distance from the centre of the arena were also analyzed. Average dispersal distance traveled by postfeeding larvae of $C$. megacephala is $45.6 \pm 24.5 \mathrm{~cm}$ for circle I, $132.6 \pm 18.7 \mathrm{~cm}$ for circle II, $225.4 \pm$ $10.5 \mathrm{~cm}$ for circle III and $315 \pm 5.8 \mathrm{~cm}$ for circle IV. Similarly, average dispersal distance traveled by postfeeding larvae of $C$. rufifacies is $42.8 \pm 15.8 \mathrm{~cm}$ for circle I, $128.6 \pm 12.6 \mathrm{~cm}$ for circle II, $214 \pm 6.5 \mathrm{~cm}$ for circle III and $306 \pm 1.5 \mathrm{~cm}$ for circle IV.

The average pupal weight for $C$. megacephala was $35.3 \mathrm{mg}$ and most pupae weighed between 31 and $43 \mathrm{mg}$. Similarly, the average pupal weight for $C$. rufifacies was $35.95 \mathrm{mg}$ and most pupae weighed between 32 and $45 \mathrm{mg}$. The average pupal weight for $C$. megacephala was $38.9 \mathrm{mg}$ in circle I, $36.5 \mathrm{mg}$ for circle II, $34.6 \mathrm{mg}$ for circle III and $31.5 \mathrm{mg}$ for circle IV. Similarly, the average pupal weight for $C$. rufifacies was $43.4 \mathrm{mg}$ for circle I, $37.7 \mathrm{mg}$ for circle II, $32.8 \mathrm{mg}$ for circle III and $29.9 \mathrm{mg}$ for circle IV.

It is obvious from the data that the lighter larvae tend to move longer distances. Larval movement takes place mainly to find a suitable pupariation site, even though the possibility that some larvae were searching for an additional source of food cannot be discarded [17]. Circle I was preferred by both the species. In other experiments where larvae of $C$. megacephala and $C$. albiceps distributed in a quadrant, $31.17 \%$ preferred quadrant I and only $15.25 \%$ went to quadrant II [18]. Greenberg [14] identified three patterns of larvae dispersal. The larvae of Lucilia sericata and Calliphora vicina were the most dispersive; $<1 \%$ of the former and only $15.5 \%$ of the latter remained at the food source. The larvae of Phormia regina, $C$. rufifacies and Muscina stabulans dispersed the least; $98 \%$ of $P$. regina, $90 \%$ of $M$. stabulans, and $84 \%$ of $C$. rufifacies remained at the food site. Cochliomyia macellaria larvae showed an intermediate response; about $50 \%$ dispersed no farther than $2.4 \mathrm{~m}$ and none moved more than $5.1 \mathrm{~m}$; $40 \%$ remained at the food source.

Godoy et al. [2] observed the oscillation in pupal frequency as a function of distance from the feeding substrate for $C$. megacephala and $C$. putoria. According to Boldrini et al. [8], these oscillations would be a consequence of larval aggregations in certain sites of the pupariation substrate. Smaller larvae travel greater distances to pupariate or in search of an additional food source. Postfeeding dispersal in blow fly larvae under laboratory conditions is typically very short but may extend for hours or even days in the field [19]. The postfeeding larval dispersal behavior and the consequent pattern of spatial distribution of pupae can be a function of greater or lesser larval susceptibility to predator or parasitoid attacks $[7,11,20,21$, 22]. Another obvious fact is that the larvae, particularly those of C. rufifacies, do not distribute themselves uniformly into the arena (Figures 1 and 2) but concentrate closer to the food source at the center. Similar observations were made by Gomes and Von Zuben [18] for C. albiceps. Student's t test along with correlation test was performed to analyze the correlation among variables [23]. The correlation between distance and weight is $-0.960(\mathrm{p}=0.0024)$ and $-0.898(\mathrm{p}=0.006)$ for $C$. megacephala and $C$. rufifacies respectively, which indicates an inverse relationship. When the Student's t test was applied, a value of -4.880 and -2.894 was obtained respectively for the two species which again means that the farther the larvae are from the centre, the lesser they weigh. Considering the variable distances for both the species, a Student's t test value of 69.68 was obtained, indicating that the mean distances for the two species are not comparable. Similarly, considering weight, Student's t value of 6.217 indicates that the weight averages for the two species are not close.

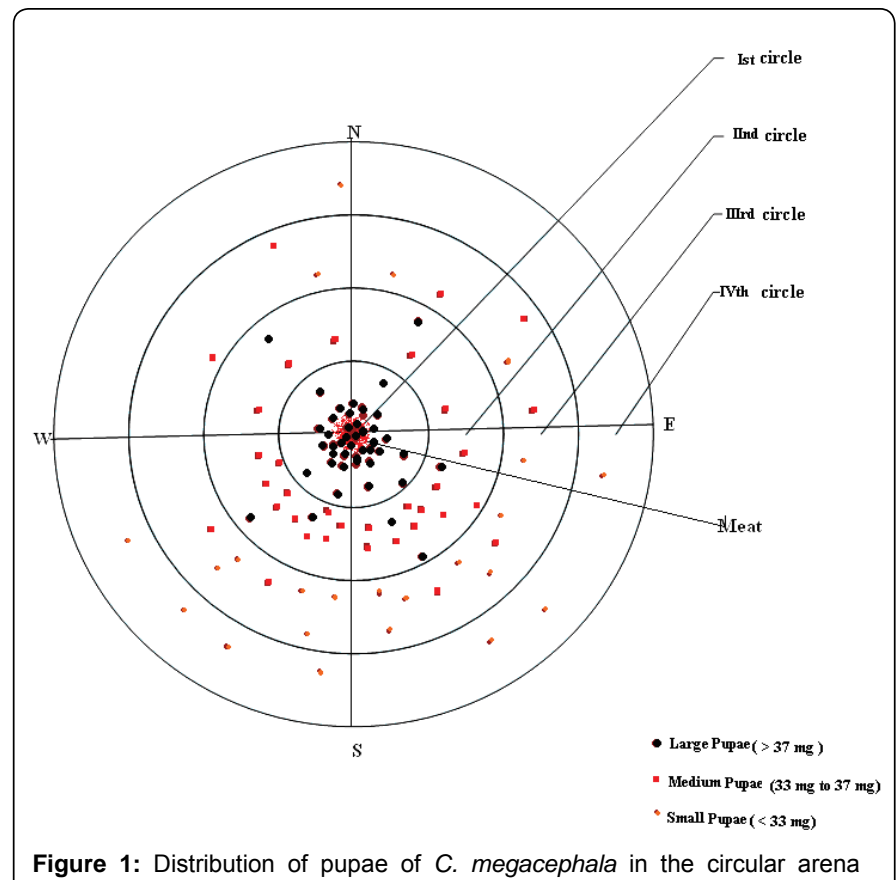

according to weight. 
Citation: Singh D, Bala M (2010) Studies on Larval Dispersal in Two Species of Blow Flies (Diptera: Calliphoridae). J Forensic Res 1:102. doi:10.4172/2157-7145.1000102

Page 3 of 3

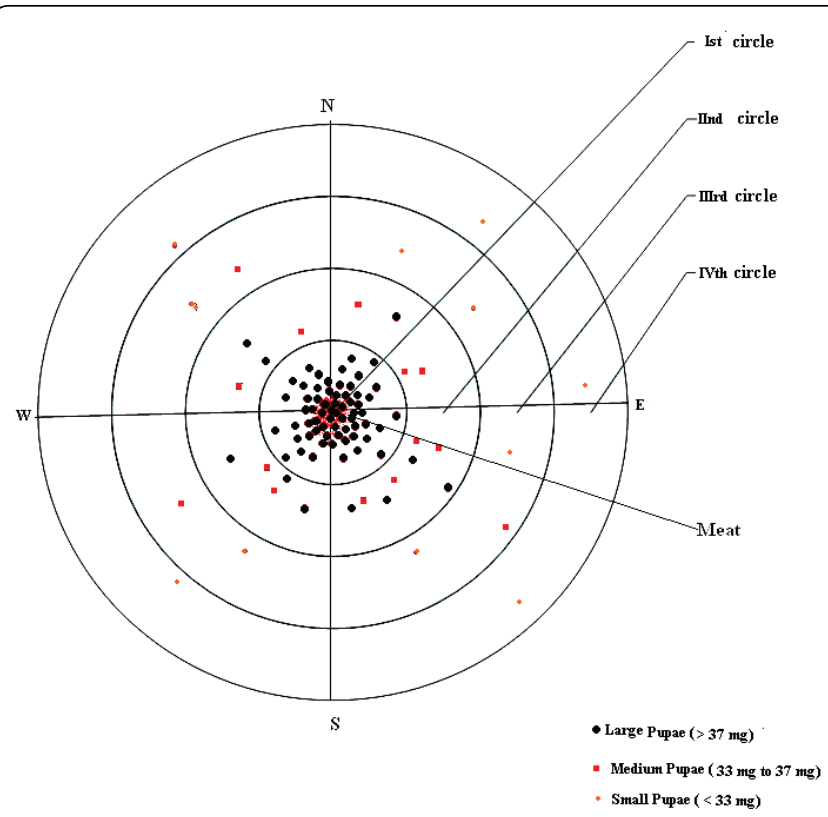

Figure 2: Distribution of pupae of $C$. rufifacies in the circular arena according to weight

\section{Conclusions}

Studies on the larval dispersal could have important implications for medico-criminal investigations as the presence of larvae and pupae in or around a human corpse could help estimate the time interval between the person's death and the moment the body was found, commonly called the minimum postmortem interval (PMI). The comparison of larval dispersal between the two species under consideration shows that the larvae of $C$. megacephala are more dispersive than that of $C$. rufifacies. Secondly, most larvae of $C$. rufifacies remained near the food site as also observed by Greenberg [14]. A reason for this behavior could be the carnivorous habits of $C$. rufifacies larvae that predate upon other larvae. Correct estimation of the PMI is one of the most important aspects of legal medicine [24], and it could be underestimated if the dispersing larvae are not taken into account [25]. It can be concluded that the investigator should be careful while drawing conclusions about minimum PMI on the basis of size of those larvae that have dispersed for considerably long distances. They may actually be representing the lot of starved larvae that left the corpse in search of a new food source because of exhaustion of supply at the primary corpse. The time taken for such dispersal should also be taken into consideration if pupae found away from the corpse are used to determine the minimum time since death. Similarly, the possibility of migration of maggots from other carrion decaying nearby should be thoroughly probed before arriving at estimation of minimum PMI.

\section{Acknowledgements}

Madhu Bala is thankful to Council of Scientific and Industrial Research, for providing financial assistance for this research in the form of Junior Research Fellowship (S. N0 09/140(141)2006 EMR-I)

\section{References}

1. Levot GW, Brown KR, Shipp E (1979) Larval growth of some calliphorid and sarcophagid (Diptera). Bull Entomol Res 69: 469-475.

2. Godoy WAC, Von Zuben CJ, Dos Reis SF (1996) Larval dispersal in Chrysomya megacephala, Chrysomya putoria and Cochliomyia macellaria (Diptera: Calliphoridae): Ecological implications of aggregation behaviour. J Appl Ent 120: 423-426.

3. Goff ML, Flynn MM (1991) Determination of postmortem interval by arthropod succession: a case study from the Hawaiian Islands. J Forensic Sci 36: 607614.

4. Greenberg B (1991) Flies as forensic indicators. J Med Entomol 28: 565-577.

5. Sukontason $\mathrm{KL}$, Sukontason $\mathrm{K}$, Narongchai $\mathrm{P}$, Lertthamnongtham $\mathrm{R}$, Piangjai $S$, et al. (2001) Chrysomya rufifacies (Macquart) as a forensically-important fly species in Thailand: a case report. J Vector Ecol 26: 162-164.

6. Oliveira-Coasta J, Mello-Patiu CAD (2004) Application of forensic entomology to estimate of the postmortem interval(PMI) in homicide investigations. Aggarwal's Internet J F Med \& Toxi 5: 40-44.

7. Peschke K, Krapf D, Fuldner D (1987) Ecological separation, functional relationships, and limiting resources in a carrion insect community. Zool Jb Syst 114: 241-265.

8. Boldrini JL, Bassanezi RC, Moretti AC, Von Zuben CJ, Godoy WAC, et al (1997) Non- local interactions and the dynamics of dispersal in immature insects. J Theor Biol 185: 523-531.

9. Atkinson WD, Shorrocks B (1981) Competition on a divided and ephemeral resource: a simulation model. J Ani Eco 50: 461-471.

10. Ives AR (1991) Aggregation and coexistence in a carrion fly community. Eco Mono 61: 75-94.

11. Hanski I (1987) Carrion fly community dynamics: patchiness, seasonality and coexistence. Eco Entomol 12: 257- 266.

12. De Jong G (1976) A model of competition for food. I. Frequency dependent viabilities. American Naturalist 110: 1013-1027.

13. Lomnicki A (1988) Population ecology of individuals. Princeton Press, Princeton, New Jersey.

14. Greenberg B (1990) Behavior of postfeeding larvae of some Calliphoridae and a muscid (Diptera). Ann Entomol Soc Amer 83: 1210-1214.

15. Kocarek $P$ (2001) Diurnal patterns of postfeeding larval dispersal in carrion blow flies (Diptera, Calliphoridae). Euro J Entomol 98: 117-119.

16. Bassanezi RC, Leite MBF, Godoy WAC, Von Zuben CJ, Von Zuben FJ, et al (1997) Diffusion model applied to postfeeding larval dispersion in blow flies (Diptera: Calliphoridae). Mem Inst Oswaldo Cruz 92: 281-286.

17. Gomes L, Von Zuben CJ, Govone JS (2002) Comportamento da dispersão larval radial pós-alimentar em moscas-varejeiras do gênero Chrysomya (Diptera: Calliphoridae): busca por novas fonts de alimento Entomol Vect 9: 115-132.

18. Gomes L, Von Zuben CJ (2003) Distribuição larval radial pósalimentar em Chrysomya albiceps (Wied.) (Diptera: Calliphoridae): profundidade, distância e peso de enterramento parapupação. Entomol Vect 10: 211-222.

19. Gomes L, Gomes G, Oliveira HG, Sanches MR, Von Zuben CJ (2006) Influence of photoperiod on body weight and depth of burrowing in larvae of Chrysomya megacephala (Fabricius) (Diptera, Calliphoridae) and implications for forensic entomology. Rev Bras Entomol 50: 76-79.

20. Goodbrod JR, Goff ML (1990) Effects of larval population density on rates of development and interactions between two species of Chrysomya (Diptera: Calliphoridae) in laboratory culture. J Med Entomol 27: 338-343.

21. Wells JD, Greenberg B (1992) Interaction between Chrysomya rufifacies and Cochliomyia macellaria (Diptera: Calliphoridae): the possible consequences of an invasion. Bull Entomol Res 82: 133-137.

22. del Bianco Faria L, Godoy WA (2001) Prey choice by facultative predator larvae of Chrysomya albiceps (Diptera: Calliphoridae). Mem Inst Oswaldo Cruz 96: 875-878.

23. Wessa P (2008) Free statistic software, office for research development and education.

24. Smith KGV (1986) A Manual of Forensic Entomology. Cornell University Press Ithaca, New York.

25. VonZuben CJ, Bassanezi RC, Von-Zuben FJ (1998) Theoretical approaches to forensic entomology : II. Mathematical model of larval development. J Appl Entomol 122: 275-278. 